ISSN 2227-7102

www.mdpi.com/journal/education

Article

\title{
Challenges for Educational Technologists in the 21st Century
}

\section{Robin Mayes *, Gloria Natividad ${ }^{\dagger}$ and J. Michael Spector ${ }^{\dagger}$}

Department of Learning Technologies, College of Information, University of North Texas, 3940 N. Elm Street, G 150, Denton, TX 76207, USA

$\dagger$ These authors contributed equally to this work.

* Author to whom correspondence should be addressed; E-Mail: robin.mayes@unt.edu; Tel.: +1-940-369-5070; Fax: +1-940-565-4194.

Academic Editor: Jing Lei

Received: 14 July 2015 / Accepted: 10 September 2015 / Published: 17 September 2015

\begin{abstract}
In 1972, Edsger Dijkstra claimed that computers had only introduced the new problem of learning to use them effectively. This is especially true in 2015 with regard to powerful new educational technologies. This article describes the challenges that $21 \mathrm{st}$ century educational technologists are, and will be, addressing as they undertake the effective integration of new technologies into K-12 educational systems and learning environments. The expanding Internet, ever more powerful mobile devices, and other innovations make the task of designing effective formal and informal learning challenging, especially in light of the high rate of change in these new technologies. While these technologies introduce many benefits, they are also causing serious threats to system security and personal privacy. Furthermore, as these technologies continue to evolve, ethical issues such as equal access to resources become imperative. Educational technologists must expand their forward-thinking leadership and planning competencies so as to ensure effective use of new technologies.
\end{abstract}

Keywords: digital divide; educational technology integration; equal access; ethics; instructional design; privacy rights; security 


\section{Introduction}

It is clear the challenges that educational technologists face regarding technology integration in learning, instruction, and performance are significant and that the current state of educational technology research reminds one of the challenge of shooting at a moving target. Moreover, as Rogers observed when presenting new research, "getting a new idea adopted, even when it has obvious advantages, is difficult" and often involves a sort of social change that alters the very structure and function of a social system [1] (p. 1). Cuban agreed and further argued that educational technology integration initiatives often go hand-in-hand with discussions about educational reform and systemic change [2]. As educational technologists are brought into a project with new information and communication technologies, changes in instructional approaches, and new learning activities it is also a challenge to keep the focus remaining on an organization's basic educational goals [3].

The field of educational technology is a dynamic discipline, and as Finger says "we can only speculate what technologies, teaching and learning might look like towards the end of this century" [4] (p. 209). However, an agreement on some basic definitions, make it easier to frame a discussion of the future of educational technology. The following are several pertinent definitions.

The Association for Educational Communications and Technology (AECT) provided a definition for the enterprise of educational technology in 1977 that states "Educational technology is a complex and integrated process of people, procedures, ideas, devices, and organization for analyzing problems and devising, implementing, evaluating, and managing solutions to those problems, involved in all aspects of human learning" [5] (p. 270).

In 2008, the AECT defined the profession of educational technology as, "The study and ethical practice of facilitating learning and improving performance by creating, using, and managing appropriate technological processes and resources" [5] (p. 280). The addition of the ethical concept to the definition was a noble attempt to move the field toward embracing best practice strategies serving the individual, organizations and society as a whole. Mayes, Bracey, Aguilar, and Allen agree with the importance of ethics as a critical consideration in the development of best practices by a profession [6].

This article focuses on K-12 contexts and defines educational technologists as the front-line professionals who are educated and trained to address the challenges of analyzing, designing, developing, implementing, evaluating and researching technology integration in educational settings. This definition does not restrict the educational technologist to one role. Principals and superintendents may have been formally trained in the educational technology discipline and have dual roles. Moreover, this article includes Patterson's 1985 conclusions that educational technologists must possess critical management level skills in the social sciences, organizational communications, problem solving and cost benefit evaluations [7]. However, because of the numerous job requirements, political and budget constraints, and the limited number of trained professionals, this article focuses the definition of K-12 educational technologists to include all those involved in the design, development, implementation and evaluation effort, as well as educational technology researchers who provide data and feedback to those aforementioned. Included are formally trained educational technologists (including department and project managers), instructional designers (including subject matter experts, content architects and various media developers), program and project evaluators, administrators and teachers and information technology specialists (including system administrators, programmers, support technicians 
and trainers) $[6,8,9]$. While it may be argued that information technologists, administrators and teachers are not normally considered educational technologists, their collaborative efforts and combined expertise in meeting educational technology and instructional design challenges are essential to any successful ETI (educational technology integration). Moreover, in small school districts the information technology specialist working in close collaboration with teachers and administrators may be the sole onsite person responsible for maintaining and improving the schools educational technology system. This is consistent with Merriam-Webster dictionary's less restrictive definition of "technology" as "the practical application of knowledge, especially in a particular area" [10]. What is noteworthy is that this definition lacks any reference to computers, email, learning management systems, etc.

This article also uses the terms "Educational Technology Integration" (ETI), "ETI solutions" and "ETI implementations". These three terms are, for the most part, interchangeable. The Technology in Schools Taskforce define educational technology integration as:

Technology [educational] integration is the incorporation of technology resources and technology-based practices into the daily routines, work, and management of schools. Technology resources are computers and specialized software, network-based communication systems, and other equipment and infrastructure. Practices include collaborative work and communication, Internet-based research, remote access to instrumentation, network-based transmission and retrieval of data, and other methods. This definition is not in itself sufficient to describe successful integration: it is important that integration be routine, seamless, and both efficient and effective in supporting school goals and purposes [11] (p. 75).

It is difficult to determine to what extent that learning and performance have been enhanced or the degree of effectiveness without both formative and summative evaluation. In addition, one cannot determine the generalizability of findings without substantial empirical research. Of particular significance are educational technology solutions that can be scaled up and across multiple contexts and sustained over a period of time so as to have a significant impact on education beyond a very specific application in one location or with regard to one situation.

\section{Challenges and Opportunities}

While every profession encounters challenges that must be met, the dynamic field of K-12 educational technology is an exceedingly challenging profession. However, educational technologists are trained in leadership, change management, problem solving and technical competencies; they tend to view these challenges as opportunities. The primary motivation is that their efforts will directly support their organization's educational goals, which typically include (a) developing basic knowledge and skills; (b) developing problem solving and critical thinking skills; and (c) developing responsible citizens and life-long learners [3,9]. While it is generally agreed that ETI solutions can effectively replace some labor-intensive educational processes (e.g., managing resources, monitoring student progress, etc.), the overall support of an organization's goals is the foremost consideration. A secondary motivation is the value gained by exposing students to modern educational technologies and preparing people for life in the 21 st century. The exposure to modern technologies often meets 
student expectations, improves student productivity, contributes to successful careers, and complements lifelong learning competencies. A third and highly important motivation is in the challenge to find solutions that are sustainable and that have an impact beyond the specific and immediate context; that is to say that educational technology research is a key factor in systemic and sustained impact and progress.

However motivated, educational technologists will encounter many challenges involving planning, people, resources and ethical issues that can jeopardize ETI solutions and outcomes. Some challenges confound small-scale ETI system upgrades or expansion work, while other challenges wreak havoc on large-scale and system-wide efforts. An understanding of these potential challenges can prepare educational technologists to meet them head-on across the modern multicultural community.

This article reviews five major challenge groups derived from a review of the literature from both the management and technical side of ET and IT implementations. While they are not necessarily unique to the 21 st century, they are becoming increasingly complex as the field of education becomes more dependent on 21 st century technologies in global multicultural environments. In addition, the widespread acceptance of these technologies has led to serious issues of public access, privacy, and security. These issues inhibit the kinds of systemic and sustainable outcomes that most educational technologists seek. While every project has its own requirements, a failure to address these five challenges has often led to less-than-stellar success rates $[12,13]$. Each challenge is discussed next.

\subsection{Assembling and Maintaining a Team of Competent Educational Technologists}

Because of the collaborative efforts needed in educational technology integrations, the human resource side of ETI projects presents major challenges and requires an educational technologist attention from the very beginning. Many organizations start by taking inventory of their human resource needs. This is a difficult challenge, as any project at this point may lack any delineation regarding scope and detailed specifications. However, a human resource department or educational development unit can begin by creating job descriptions which identify the competencies needed for educational technology planning and implementation. The job descriptions can be used for reassigning existing employees, recruiting new employees or contracting consultants. Some examples of common job descriptions that are relevant to successful ETIs are:

Educational technologists often lead educational technology teams. They are often trained as instructional designers and have (a) a strong foundation in the studies of the behavioral sciences; (b) knowledge and skills in project management; (c) competencies in effective communications; (d) strong instructional design and media selection experience; and (e) proficiencies in program performance evaluation [8].

Instructional designers design and develop educational systems and content deliverables. They use research-based learning principles to creatively design the appearance, organization and functionality of learning systems. These individuals are best situated to lead and manage an educational technology integration effort as their knowledge and expertise spans the entire life-cycle of an instructional effort. Instructional designers are critical educational technologists and core to an effective application.

Multi-media developers are responsible for assisting with the development of educational technology multimedia for instructor-led, eLearning, mLearning, and blended learning solutions. They 
work closely with instructional designers, as well as the instructional technology team, to create and deliver multimedia based curriculum deliverables.

Technical support specialists or user support specialist assist users who are in need of training or are having issues with the computers or the installed software. Moreover, they provide support for peripherals such as external drives, printers and scanners, plus network or Internet connectivity issues. In small organizations these tasks maybe performed by a network engineer.

Network engineers are responsible for the whole ICT system including selecting, installing and configuring all hardware and software for workstations and network services. They support the administration of network servers and server clusters. They manage user accounts, grant and deny permissions, maintain email services, monitor anti-virus and anti-spam activity and oversee hardware, software and network intrusion security. Furthermore, they monitor system performance and implement system performance tuning and troubleshooting analysis of servers, workstations and associated systems. They manage and maintain data back-up and restorations as well as keeping back-up power systems operational. They are also responsible for documenting system changes, identified system problems and their resolutions for future reference. While network engineers are not considered educational technologists, their involvement early in any ETI effort is important, which is also true of software engineers and programmers.

Computer software engineers use research-based functionality requirements and user interface design principles to design and document computer program specifications. They also assist media developers and programmers to ensure effective and consistent designs of all resources involved.

Computer programmers write source code modules that convert program design specifications into a set of instructions a computer can follow. They test their program to look for errors and then rewrite these programs until they operate without errors, consistent with design requirements. Computer programmers continue to evaluate programs that are in use, making updates and adjustments as needed.

Software developers integrate the task functionality of both computer software engineers and computer programmers to develop software applications in a more agile environment.

As with all organizational challenges, there are barriers, due in part to the different backgrounds and interests of those involved. Human resource requirements are influenced by politics and budgets. Hall, states that 'Unfortunately, many districts cannot hire a network architect and don't have the funding to implement an end-to-end solution" [14] (p. 2). Additionally, those responsible for the initial planning may not be trained instructional designers and often lack adequate educational technology and instructional design expertise to make informed decisions about approach, technology, and resource requirements [14]. To handle these issues, Dorsey [15] recommends that there should be at least one person with strong technical leadership skills and experience on the team. In addition, our recommendation is to ensure than an experienced instructional designer leads the effort from initial planning through implementation and evaluation.

\subsection{Planning and Organizing the Project Processes}

Once an ETI team has been assembled, the challenges of planning and organizing become even more important and often fall on the educational technologist to lead the effort. Hall emphasizes the importance of using appropriate strategic planning and the avoidance of reactionary 
implementations [14]. Many educational technologists are competent in instructional design process models such as ADDIE (Analyze, Design, Develop (or Acquire), Implement and Evaluate) [16] or Tennyson's Fourth Generation Instructional Development Model [9,17,18]. ADDIE is a project management methodology that provides a high-level overview and is best suited when a project can be completed in distinct, but potentially overlapping steps [16]. ADDIE is also useful in keeping a project team organized around key processes. Tennyson's Fourth Generation Instructional Development model is based on the activities of various team members and is well suited for large projects that are dynamic and subject to change as the project matures $[9,17,18]$ While ADDIE provides a useful conceptual framework, Tennyson's more detailed model focuses on what members of the project team do and, consequently, it is effective in managing the dynamics of complex projects, which are pervasive in education.

Fish suggests that project management tools such as Microsoft Project ${ }^{\circledR}$ can be instrumental in guiding an ETI by creating awareness in these specific areas:

- Project planning

- Work breakdown structures

- Working within budget constraints

- Resolving the issues in handling competing resources

- Running simultaneous projects [19] (p. 41)

\subsection{Systematically Identifying ETI System Requirements}

The third K-12 challenge group that educational technologists face is the gathering and management of system requirements [20]. This process is analogous to identifying the destination before planning the route. The most difficult challenge that educational technologists face is gaining an understanding of the underlying problems or needs, and then what is required to address and resolve those issues. Many times, decision makers focus on the symptoms of a problem (e.g., poor student performance in mathematics) rather than the underlying causes (e.g., a poorly structured curriculum or mismatches between learning goals and objectives and associated learning activities and assessments).

A needs assessment is an approach that is used to identify the requirements, both apparent and underlying, by taking current levels of achievement into account [20]; instructional designers are typically trained in conducting needs assessments. The data collection process for a needs assessment should include a collection of stated needs by multiple stakeholders supplemented by observed symptoms representing multiple and diverse perspectives. The gathered data is an opportunity for identifying themes and specific details. For example, a school system may be having trouble getting educators to adopt a particular learning management system. The administrators may have identified the symptom as limited use of a new technology. Without further investigation, an educational technologist might conclude that what is needed is a stronger policy encouraging adoption or incentives to using the new technology. However, with further investigative techniques commonly used in a needs analysis, including interviews and observations, the investigators might identify an underlying problem. The educational technologist might find that the challenge involves system anomalies or how the system has been configured. They might conclude that modifications to the interface or additional capabilities are required. They may also find a need for additional training. 
Employing a needs assessment strategy is an opportunity to gather evidence that defines the underlying problem(s) by involving the various stakeholders and using that information to evaluate potential solutions.

While time is a cost driver (especially the time of the various members of the team), educational technologists cannot be expected to gather and document requirements in a single iteration. Once solutions and approaches begin to emerge, reiterations of the needs assessment and cost estimation processes are required to further clarify and define system requirements. Nevertheless, the revisiting and further analysis of requirements, resources, local policies, practices, and the knowledge and experiences of users, risks increasing the scope of a project. An expanded scope and additional expectations are common occurrences in educational technology projects that add to existing challenges. In other words, the larger the number of possible solution details, the more difficult ETI decision-making becomes. Adding to this complexity may be budget constraints and exaggerated claims made by product and service vendors. Spector offers words of caution for projects suffering from uncontrollable growth:

It is not generally wise to try to change everything all at once, although there are occasions when such a strategy has worked well. More typically, it is safer to adopt a graceful evolution approach to change. Remaking the entire world of education in one fell swoop has been the fool's folly of too many educational researchers and reformers [9] (p. 208).

In summary, effective ETI needs assessments involve (a) gathering input from stakeholders; (b) exploring diverse interests and strategies; and (c) analyzing various solutions, while maintaining a focus on the organization's specific educational goals and objectives. It is important to involve representative teachers and students, consistent with user-centered and participatory design approaches [21,22]. Moreover, all decisions regarding any acquisitions should be diligently examined regarding ethical implications [23]. The following four subsections are directly related to relevant areas that must be addressed in the above discussed needs analysis.

\subsubsection{System Requirements for a Content Delivery System}

While most novices see hardware as the real challenge in designing a curriculum content delivery system, it is the software or provided services that are more critical. Training teachers and other key players on the effective use of hardware and software is perhaps the most critical and also the most overlooked challenge. There are four simple questions that need to be answered: (1) Does this software/service perform as required now? (2) In the future, will it perform as required then? (3) Can the software/service be modified or configured as required? (4) What training and professional development are required to ensure the sustainability of the effort? To be able to answer these questions, planners must know what is needed now and likely to be needed in the future. This is where a compilation of gathered system requirements is essential. The requirements and needs analysis should generate lists that can be checked off and signed by the project manager to ensure a comprehensive solution. This is a critical step often over-looked by ETI project teams. Finally, no selection decision should be made regarding software or provided services until the educational technologists and especially the instructional designers have reviewed or addressed all of the challenges. 


\subsubsection{System Requirements for Learning Content}

The challenge of educational content reform appears to be a global phenomenon. Organizations like UNESCO and their Education for All (EFA) initiative and OECD (Organization for Economic Co-operation and Development) Program for International Student Assessment (PISA) have keystone goals and objectives for improving the quality of education [4]. China, starting at the turn of the century, recognized the importance of educational reform as a means for competing globally [24,25]. China formulated new curriculum designs that moved from rote memorization and examination to curricula that developed creative and independent thinking students/citizens. This process is ongoing in China although there is still a great deal of emphasis on memorization and testing. In the United States, many states have signed on to the Common Core initiative [26]. The Common Core initiative establishes K-12 competency levels in math and English language arts. Thus, instructional designers have a set of guidelines they may follow. Because of the potential scale that the Common Core program can reach, state governments and foundations can fund extensive research and developmental programs. However, the challenge for the educational technologist will be matching the needs of the organization with the available products or developing new content. This is why research and evaluation are critical concerns of educational technologists.

\subsubsection{System Requirements for Addressing the Needs of Diverse Learners}

Educational technologists must understand ethical requirements, many of which arise from the diversity of their students. Today's students are diverse and pose significant challenges for an ETI solution, especially those involving multi-cultural and multi-lingual groups [27]. Significant group and individual differences in abilities, culture, language, ethnicity, gender, previous educational experience, and optimal modes for individual learning must be accommodated if the digital divide is to be breached. One of the keystone goals of UNESCO and their Education for All (EFA) initiative and OECD (Organization for Economic Co-operation and Development) Program for International Student Assessment (PISA) is improving educational access for all [4]. This ethics-driven goal is particularly important in countries where socio-economic class or gender has typically been a barrier to elementary and secondary education. ETI can worsen the digital divide if not planned and implemented with the needs of all in mind.

In addition, new technologies can help people who have difficulties (e.g., in speaking, typing, writing, remembering, pointing, seeing, hearing, learning, walking, etc.) cross the digital divide. Commonly referred to as assistive technologies (AT), these technologies include pieces of specialized equipment, software and product systems that are used to increase, maintain, or improve the functional capabilities of individuals with disabilities [28]. Strobel, Arthanat, Bauer and Flagg [29] provide examples of changes in hardware and software technologies addressing the special needs of students. One result is that a broader range of students can now be included in course and curriculum planning and implementation. However, educational technologists need to differentiate between what an ETI solution can accommodate, what further AT may be required, and what resources and grants are available to integrate AT. Designing for all learners in a variety of situations using different devices and platforms begins during the needs assessment phase of an effort. The challenge for educational 
technologists is to integrate advanced learning technologies, including AT, promote their effective use, and manage their availability including proper maintenance, training and support. Coleman [30] has observed in her research that many AT devices, once acquired, often go unused and are in various states of neglect. This happens to be a phenomenon not restricted to just assistive technologies.

\subsubsection{System Requirements for Supporting any Device, Anytime, Anywhere, any Task}

Educational technologists have a long history of supporting various hardware technologies and platforms. The path starting with centralized processing using mainframes, then moving to desktop independence and now returning to centralized processing topologies using the Cloud, symbolizes the full-circle path that technology has taken. As the Internet has evolved, the challenge of a new educational technology model has emerged [31]. It is a combination of the cloud computing for anywhere, anytime, any device, any process (programs and data being stored on the Internet) and what has been referred to as Web 2.0 [32,33] and Web 3.0 technologies [34] (e.g., social networking and highly interactive Internet or web-server based applications and the Semantic Web). These Web technologies shift functionality from workstation based stand-alone environments to standardized Web browsers and Web servers, and eliminate the hardware and operating system dependencies that previously had to be individually accommodated. Secure and responsive applications and websites are critical [35]. As educational technologists work with new challenging hardware designs such as wearable and implantable devices, it will be Web 2.0 and Web 3.0 technologies that enable these devices to work in familiar ways. While the details of this challenge is beyond the scope of this article, it is safe to say that educational technologists must continually research and seek training on device and software functionality, as well as interconnectivity issues that include ethically compliant challenges of access, privacy, security and even environmental issues [36].

\subsection{Redefining and Refining the Roles of Teachers}

The New Media Consortium's Horizon Report 2015 K-12 Edition [37] emphasizes that teachers' roles will change as schools' pedagogical approaches become more student-centered. Graves, Abbitt, Klett and Wang [28], along with many others, predict that teachers will be required to serve as facilitators and mentors in problem-based contexts and less as deliverers of content. This implies a need for new teacher training and professional development efforts, potentially putting additional training and support responsibilities with the educational technologist and ETI teams. Technology-based pedagogies like the flipped classroom and hybrid learning require new interactions between teachers and students [9]. Regardless of whether teachers manage computer labs, computerized classrooms, or online sessions, teachers will require training and administrative support for ongoing professional development, ETI competency preparation, and staff collaboration efforts. Additionally, and just as important, teachers need the time to use these technologies to reduce their apprehension and raise their self-efficacy levels. Without such time and training, teachers may find that educational technology is just another challenge they do not have the time to address. O'Hanlon stresses the importance for positive teacher acceptance, saying that: 
With many teachers, the way a technology is introduced into the academic environment can mean the difference between adoption and abandonment. If teachers believe they are being forced into using it, they will resist, especially if you don't show them what value it will bring to their classroom [38] (p. 33).

However, just understanding how to use a new technology is not sufficient. Digital stalking and bullying behaviors bring a new depth to monitoring online social activities. Anderson describes cyber-stalking as:

Cyber Stalking is very similar to traditional stalking in that an individual enters a person's life and threatens and intimidates the person. Cyber Stalking is done using electronic means such as chat rooms, e-mail, blogs, and other forms of verbal online abuse (flaming). Cyber Stalking also includes identity theft. Identity theft can either be electronic misrepresentation (the stalker has an online presence that mimics the victim) or physical identity theft (the stalker represents himself either in person or verbally as the victim) [39] (p. 18).

Very closely related to cyber-stalking is cyber-bullying. Martínez-Valderrey and Garaigordobil [40] provide us with a definition of cyber-bullying based upon and Smith et al. [41] and Olweus's [42] definition of bullying:

Cyberbullying is an aggressive and intentional behavior repeated frequently over time by means of the use, by an individual or group, of electronic facilities targeting a victim who cannot easily defend him- or herself [40] (p. 45).

The two definitions reflect the seriousness of these behaviors and the difficulty that a teacher or school official faces in addressing them. Between these new and sometimes mandated responsibilities and the challenges that accompany new technologies, a teacher may become overwhelmed. Teachers will need to be aware of how to scrutinize the cyber-environment looking for evidence of these transgressions. In support of their diligent efforts, school policies will have to be clear and the required training and professional development provided.

Administrators may also have to address the fears of some teachers that technologies may eventually replace them, even though this concern is largely unfounded [9]. One solution is to insure that teachers and support staff have the opportunity to contribute to planning and implementing new solutions, receive the appropriate training and professional development, and have access to ongoing support. In addition, the administration should remind teachers that while formative and summative assessments may become fully automated, the interpretation of the data and the selection of the appropriate interventions will require competencies that teachers already possess.

\subsection{Managing Resources, Maintenance and Support}

The Horizon Report 2015 K-12 Edition [37] acknowledges that education administrators are continually challenged by budgetary constraints. While government grants, industry support and citizen initiatives are helpful and often provide seed funds to start ETI solutions, the burden of ongoing expense of upgrades and support remains with the school system. When budgets are restricted, an ETI 
solution with maintenance and support expenses may put an ETI solution out of reach for some institutions. In addition, when system purchasing decisions are made, those involved often lack the expertise needed for sound technology acquisitions. Conversely, Grothe finds that those who do have the technological expertise often lack an understanding of instruction [14]. These reciprocal competency shortfalls exacerbate maintenance and support issues making it difficult and frustrating for all involved. Gura and Bernard Percy quote Grohe who further states that "...those who understand the critical nature of updating and upgrading technology are stunned by the cost implications" [14] (p. 2).

In response to escalating maintenance and support costs educational technologists must consider all viable solutions. ETI cloud-based solutions such as Software as a Service (SaaS), Platform as a Service (PaaS), and Infrastructure as a Service (IaaS) are reducing start-up expenditures as well as reducing maintenance and support expenditures [43]. Greengard [31] finds extensive support for such services and points to a growth rate exceeding $40 \%$ for SaaS. This trend removes many infrastructure responsibilities and aggravation from the educational institution and places these responsibilities (managing resources, maintenance, and support) on vendors. If these services keep up with the latest technologies and provide responsive service applications at affordable rates, employing Web/Cloud-based educational technology solutions may be the reality for the long term [35].

\section{Ethical Considerations for Security, Privacy, and Public Access}

However, there is a dark side. Since the advent of the Internet, security and privacy challenges have become serious as have maintenance, training and support issues that educational technologist must address. Denial of service (DoS) attacks are the first level of assaults that challenge the integrity of any information system [44]. Cyber-attacks such as "Click jacking" (navigational redirection) [45], "Spear phishing" (targeted information gathering) [46], and "Cross-site scripting" (embedded SQL statements entered in non-validated input fields [47] must be anticipated and prevented by enforcing strong security protocols and policies. Educational technologists must be aware of harmful application plug-ins and guard all hardware such as cameras and microphones from hardware hijacking software.

Experience shows that losses suffered from cyber-attacks and other breaches in security and privacy can be an expensive lesson for an individual or an organization. Both student and employee personal information data are targets for cyber-criminals. Opara and Bell report that:

Cybercriminals now use social networks to spy on their victims, to collect even more personal and confidential information, to then turn right around and use the information they have stolen to target these same individuals for specific and malevolent purposes [48] (p. 16).

Educational technologist must meet mandated compliancy to governmental and commerce-driven regulations such as data collection on Personally Identifiable Information (PII), Payment Card Industry Data Security Standard (PCI DSS), and Health Insurance Portability and Accountability Act (HIPAA) [49]. Regulation compliancy can be a fulltime job for a member of the educational technology team.

Another important ethical consideration tied to security is protecting children from inappropriate connections and content [50]. Access outside of an organization, i.e., the Internet, has made it essential 
to approve (sanction) or disapprove (censor) access to various websites and their content using Web proxy technologies. However, as Olagunju describes in his article, an educational technologist must possess the legal expertise on what governments define as a violation of the freedom of speech liberties and legitimate efforts to protect children [51]. He continues by citing Dorman from 1997 [52] (p. 12) with guidelines for internet usage by children as the potential remedy for these issues:

- Children using the Internet should be supervised in the same way they are when viewing television;

- Parents, teachers, and schools may purchase a filtering device, which can filter many pages that parents and teachers might consider harmful or offensive;

- Children should avoid bulletin boards and chat rooms, where they are introduced to strangers;

- Children should be taught how to use the Internet to find the information they need and how to avoid useless and harmful sites;

- Teachers should follow school acceptable-use policies and procedures developed for student and faculty use of the Internet.

As early as 1986, the concern of equitable access to educational technology has been and still is considered a challenge [53]. Now commonly referred to as the "Digital divide... a barrier separating persons with digital skills and access to the online resources from persons who do not have the skills or access to computers and the Internet" [54] (p. 315) has been brought to the forefront as technology has become increasingly important to education. Darling-Hammond, Wilhoit and Pittenger [55] (p. 31) argue that "addressing the opportunity gap that has allowed inequalities in resources to deprive many students of needed opportunities to learn" as key to educational improvement. It is the ethical responsibility of the educational technologist to make every attempt to encourage and coordinate efforts to empower all students with the required digital skills and access to any device (mobile or stationary) with the needed connectivity so that they may cross the digital divide [35].

\section{Conclusions}

Educational technologists have successfully addressed a wide range of challenges emanating from various directions, including the Internet, a plethora of new intra/interconnected devices and a broad selection of software products and services. While educational technology advances have facilitated 24-h access to a wealth of educational content and collaborative learning activities, they also raise challenging ethical issues such as an ever increasing digital divide, system security, organizational and personal privacy issues. Keeping a focus on learning and instruction in the midst of the technology explosion is an ongoing challenge.

The human factor, even with all of the research and advances in the social sciences, is still a challenge in an ETI. Educational technologists must anticipate user needs as well as shifts in attitudes, expectations and belief systems that can influence and compromise collaboration efforts thereby affecting ETI outcomes [56].

Selecting the content and delivery system can also be a daunting task. This is often left to administrators and outside technology experts who include vendors, thus introducing biases that may not be well aligned with learning and instructional goals and needs. A real opportunity for the educational technologist is promoting the idea that teachers have a stake in most ETI efforts. By 
addressing teachers' beliefs and experiences the educational technologist can successfully reduce their resistance to technology impacted pedagogical change [57]. While the need to empower learners is widely recognized as key to increasing learning engagement, likewise there is a need to empower teachers so as to increase their commitment to technology-enhanced learning and instruction.

Finally, accounting for the diversity of cultures, the wealth of human creativity, and the dynamic nature of ETI challenges, a piece of advice that Landsberger recorded in an interview with Spector seems appropriate. Spector cautions "I doubt that there is a single right solution that works for all or most situations." [58] (p. 10). His advice suggests that educational technologists should have clear expectations but be prepared to make changes based on evidence.

While it is beyond the scope of this article to recommend specific solutions, this article concludes with some lesson-learned suggestions proposed by Ehrmann:

- Don't implement a change strategy by delegating each part of it to a different stakeholder - this recommendation for faculty, that one for the information technology unit, a third for administrators, a fourth for the assessment staff. Instead, work with a team composed of people from all those groups and more;

- Simultaneously upgrade content, deepen learning, and improve the program's ability to attract and retain a variety of students;

- $\quad$ But in doing so, take your time;

- Use technology as a lever for change, but slow down. Don't leap from one hot technology to the next;

- Find ways for faculty and students to save time [59] (p. 16).

In short, if educational technologists are to meet the challenges of the 21 st century, they must act in ethical ways as inquirers, developers, and managers. They should be driven by specific questions and needs, consider alternative means to accomplish desired outcomes and commit the time and resources needed for success. Finally, educational technologists must accept and manage change and adaptations along the way and understand the implications of equal access across the digital divide while maintaining system security and personal information privacy.

\section{Acknowledgments}

This paper represents the views of the authors based on their review of the literature and their experience with a wide variety of learning and instructional environments over a collective period of approximately 100 years. We are grateful to our mentors on whose shoulders we stand, including Robert M. Gagné, M. David Merrill, D. H. Jonassen, Joost Lowyck and Sanne Dijkstra.

\section{Author Contributions}

The authors worked on this piece in close collaboration and have contributed equally to its development.

\section{Conflicts of Interest}

The authors declare no conflict of interest. 


\section{References}

1. Rogers, E.M. Diffusion of Innovations, 5th ed.; Free Press: New York, NY, USA, 2003.

2. Cuban, L. Oversold and Underused: Computers in the Classroom; Harvard University Press: Cambridge, MA, USA, 2001.

3. Natividad, G.; Mayes, R.J.; Choi, J.; Spector, J.M. Balancing stable educational goals with changing educational technologies: Challenges and Opportunities. E-Mentor 2015, 1, 83-94.

4. Finger. G. eLearning: Exploring Digital Futures in the 21st Century. Educ. Sci. 2014, 4, 209-212.

5. Januszewski, A.; Persichitte, K. A history of the AECT's definitions of educational technology. In Educational Technology: A Definition with Commentary; Januszewski, A., Molenda, M., Eds.; Lawrence Erlbaum Associates: New York, NY, USA, 2008; pp. 259-282.

6. Mayes, R.J.; Bracey, P.S.; Aguilar, M.G.; Allen, J.M. Identifying Corporate Social Responsibility (CSR) Curricula of Leading U.S. Executive MBA Programs. In Handbook of Research on Business Ethics and Corporate Responsibilities; Palmer, D., Ed.; Business Science Reference: Hershey, PA, USA, 2015; pp. 179-195.

7. Patterson, A.C. Preparing Educational Technologists. Train. Dev. J. 1985, 39, 38-39.

8. Spector, J.M. Foundations of Educational Technology: Integrative Approaches and Interdisciplinary Perspectives, 2nd ed.; Routledge: New York, NY, USA, 2015.

9. Spector, J.M. Emerging educational technologies and research directions. Educ. Tech. Soc. 2007, $16,21-32$.

10. An Encyclopædia Britannica Company. Technology. Merriam-Webster. Available online: http://www.merriam-webster.com/dictionary/technology (accessed on 2 January 2015).

11. Technology in Schools Task Force. Suggestions, Tools, and Guidelines for Assessing Technology in Elementary and Secondary Education. Retrieved March 2007 from the National Center for Education Statistics. Available online: http://nces.ed.gov/pubs2003/2003313.pdf (accessed on 27 May 2015).

12. Ely, D.P.; Plomp, T. The Promises of Educational Technology: A Reassessment. Int. Rev. Educ. 1986, 32, 231-249.

13. Volkema, R.J. Designing Effective Projects: Decision Options for Maximizing Learning and Project Success. J. Manag. Educ. 2010, 34, 527-550.

14. Gura, M.; Percy, B. Technology infrastructure: Education decision-makers need to understand the importance of creating and maintaining an up-to-date technology infrastructure. Classroom. 2006. Available online: http://www.edtechmagazine.com/k12/article/2006/10/technology-infrastructure (accessed on 18 May 2015).

15. Dorsey, P. Top 10 reasons why systems projects fail. Dulcian. Inc. 2000. Available online: http://www.rrsg.ee.uct.ac.za/courses/EEE4084F/Reading/Lect21-Dorsey_Top10ReasonsSystems ProjectsFail.pdf (accessed on 18 December 2014).

16. Huang, S.; Cho, Y.; Lin, Y. ADDIE Instruction Design and Cognitive Apprenticeship for Project-Based Software Engineering Education in MIS. In Proceedings of the 12th Asia-Pacific Software Engineering Conference, Taiwan, 15-17 December 2005. 
17. Tennyson, R. Instructional Systems Development: The Fourth Generation. In Automating Instructional Design: Computer-Based Development and Delivery Tools; Tennyson, R., Barron, A., Eds.; Springer: New York, NY, USA, 1995; pp. 33-78.

18. Spector, J.M. Foundations of Educational Technology: Integrative Approaches and Interdisciplinary Perspective; Routledge: New York, NY, USA, 2012.

19. Fish, L.A. Undergraduate and Graduate Project Management Development Using Microsoft Project. Bus. Educ. Innovat. J. 2011, 3, 33-42.

20. Ogrezeanu, A.; Ogrezeanu, A. Benefits and use of needs assessment and impact assessment for the management of elearning programs: Case study on a large eLearning project for teachers. The International Scientific Conference eLearning and Software for Education, Bucharest, Romania, 24-25 April 2014; Volume 3, pp. 543-550.

21. Barovic, V.; Pralica, D. Digital media technologies in the implementation of the course "reporting in natural disasters and accidents". e Learn. Softw. Educ. 2014, 3, 43-49.

22. Spector, J.M.; Anderson, T.M. Integrated and Holistic Perspectives on Learning, Instruction and Technology: Understanding Complexity; Kluwer Academic Press: Dordrecht, The Netherlands, 2000.

23. Martin, S. Professional Ethics. TechTrends 2012, 56, 10-12.

24. Intel Corporation. Research highlights improved teaching and learning through the 1:1 elearning initiative in Shanghai. Intel Educational Research. 2012. Available online: http://www.intel.com/content/dam/www/program/education/us/en/documents/Intel\%20Education \%20Research\%20Summary/intel-education-research-summary-prc-web.pdf (accessed on 14 September 2015).

25. Tan, C. The culture of education policy making: Curriculum reform in Shanghai. Crit. Stud. Educ. 2012, 53, 153-167.

26. Common Core. Common core state standards initiative: Preparing America's students for success. Available online: www.corestandards.org (accessed on 18 March 2015).

27. Berg, J. Dimensions of diversity. ASBMB Today, 2012. Available online: http://www.asbmb.org/ asbmbtoday/asbmbtoday_article.aspx?id=18258 (accessed on 15 December 2014).

28. Graves, S.M.; Abbitt, J.; Klett, M.D.; Wang, C. A mentoring model for interactive online learning in support of a technology innovation challenge grant. J. Comput. Teach. Educ. 2009, 26, 5-16.

29. Strobel, W.; Arthanat, S.; Bauer, S.; Flagg, J. Universal design for learning: Critical need areas for people with learning disabilities. Assist. Technol. Outcomes Benefits 2007, 4, 81-98.

30. Coleman, M.B. Successful implementation of assistive technology to promote access to curriculum and instruction for students with physical disabilities. Phys. Disabil. Educ. Relat. Serv. 2011, 30, 2-22.

31. Greengard, S. TOP 10 IT Trends for 2009. Baseline 2008, 12, 20-25.

32. Lehman, R.; Conceicao, S. Creating a Sense of Presence in Online Teaching; San Jossey Bass: San Francisco, CA, USA, 2011.

33. Tunks, K.W. An introduction and guide to enhancing online instruction with Web $2 / 0$ tools. J. Educ. Online 2012, 9, 1-16.

34. Chisega-Negrila, A. Web 3/0 in education. e Learn. Software Educ. 2012, 1, 455-460.

35. Kim, B. Responsive Web Design, Discoverability, and Mobile Challenge. Libr. Technol. Rep. 2013, 49, 29-30. 
36. Yeaman, A. If It Was Illegal, the Technology Wouldn't Allow It. Techtrends 2015, 59, 11-12.

37. NMC. NMC Horizon Report > 2015 K-12 Edition. 2015. Available online: http://www.nmc.org/ publication/nmc-horizon-report-2015-k-12-edition/ (accessed on 31 March 2015).

38. O'Hanlon, C. Resistance Is Futile. T.H.E. J. 2009, 36, 32-36.

39. Anderson, W.L. Cyber Stalking (Cyber Bullying)—Proof and Punishment. Insights Changing World J. 2010, 4, 18-23.

40. Martínez-Valderrey, V.; Garaigordobil, M. Effects of Cyberprogram 2.0 on "face-to-face" bullying, cyberbullying, and empathy. Psicothema 2015, 27, 45-51.

41. Smith, P.; Mahdavi, J.; Carvalho, M.; Fisher, S.; Russell, S.; Tippett, N. Cyberbullying: Its nature and impact in secondary school pupils. J. Child. Psychol. Psychiatr. 2008, 49, 376-385.

42. Olweus, D. Bullying at School: What We Know and What We Can Do; Blackwell: Oxford, UK, 1993.

43. Nasr, M.; Ouf, S. A proposed smart e-learning system using cloud computing services: PaaS, IaaS and Web 3/0. Int. J. Emerg. Technol. Learn. 2012, 7, 19-24.

44. Mohan Kumar, K.P.; Aramuthan, M.; Devi, T.U. Genetic-SVM Based Intrusion Detection System for DoS Attacks. Int. J. Appl. Eng. Res. 2015, 10, 20081-20092.

45. Rapoza, J. Powerless over clickjacking. eWeek. 2008, 25, 47.

46. Goral, T. Keeping cyber attacks at bay. Univ. Bus. 2014, 17, 34.

47. Manivannan, S.S.; Sathiyamoorthy, E. The four tier validation system to prevent the Web application session hijack attacks by defending the cross site scripting attacks. Int. J. Appl. Eng. Res. 2014, 9, 25757-25767.

48. Opara, E.U.; Bell, R.L. The relative frequency of reported cases by information technology professionals of breaches on security defenses. Int. J. Glob. Manag. Stud. Prof. 2011, 3, 15-28.

49. Silver, H.R.; Clark, L.W. New HIPAA Rules Regarding Genetic Information Affect Employers, Group Health Plans, Health Insurers, and Healthcare Providers. Empl. Relat. Law J. 2013, 39, 35-39.

50. Moreno, M.A.; Egan, K.G.; Bare, K.; Young, H.N.; Cox, E.D. Internet safety education for youth: Stakeholder perspectives. BMC Public Health 2013, 13, 1-6.

51. Olagunju, A.O. Harmonizing the Interests of Free Speech, Obscenity and Child Pornography on Cyberspace: The New Roles of Parents, Technology and Legislation for Internet Safety. ERIC. 2008. Available online: http://www.eric.ed.gov/contentdelivery/servlet/ERICServlet? accno=ED502269 (accessed on 5 March 2015).

52. Dorman, S.M. Internet safety for Schools, Teachers, and Parents. J. Sch. Health 1997, 67, 355.

53. Dubois, P.A.; Schubert, J.G. Do Your School Policies Provide Equal Access to Computers? Are You Sure? Educ. Leadersh. 1986, 43, 41-44.

54. Muresan, M.; Gogu, E. Overcoming the Digital Divide for facilitating the elearning process. The International Scientific Conference eLearning and Software for Education, Bucharest, Romania, 2014; Volume 3, pp. 310-315.

55. Darling-Hammond. L.; Wilhoit, G.; Pittenger, L. Accountability for college and career readiness: Developing a new paradigm. Educ. Policy Anal. Arch. 2014, 22, 1-86.

56. Ertmer, P.A.; Ottenbreit-Leftwich, A.T. Teacher Technology Change: How Knowledge, Confidence, Beliefs, and Culture Intersect J. Res. Technol. Educ. 2010, 42, 255-284. 
57. An, Y.; Reigeluth, C. Creating Technology-Enhanced, Learner-Centered Classrooms: K-12 Teachers' Beliefs, Perceptions, Barriers, and Support Needs. J. Digital Learn. Teach. Educ. 2011, $28,54-62$.

58. Landsberger, J. An interview with Michael Spector. Linking Research \& Practice to Improve Learning. TechTrends 2008, 52, 9-13.

59. Ehrmann, S.C. Taking the long view: Ten recommendations about time, money, technology, and learning. Change 2010, 42, 16-22.

(C) 2015 by the authors; licensee MDPI, Basel, Switzerland. This article is an open access article distributed under the terms and conditions of the Creative Commons Attribution license (http://creativecommons.org/licenses/by/4.0/). 